\title{
Elderly persons who live alone in Brazil and their lifestyle
}

\section{Abstract}

Objective: to assess the prevalence of elderly persons living alone in Brazil, based on covariates of health status, behavior and socio-demographic characteristics. Method: data from 11,967 individuals (aged 60 or over) were obtained from the National Health Survey (Brazil, 2013). Living alone was defined as residing in a one-person household. The prevalence of individuals living alone was stratified by socio-demographic conditions and geographic region. Living alone was also assessed as a factor for outcomes of physical functioning, behavior and health conditions. Poisson regression models were used to evaluate the prevalence ratios and a 95\% confidence interval was applied. Results: in Brazil, $15.3 \%$ of people aged 60 years and over live alone. This condition is more prevalent in higher income regions; however, more lower-income individuals were affected. Prevalence was higher among women and individuals aged 75 years or more. Living alone was associated with difficulties in instrumental activities of daily living (prevalence ratio 1.15 ; $95 \%$ confidence interval 1.04-1.28); the reporting of an illness in the two prior to the study ( $\mathrm{PR}=1.35 ; 95 \% \mathrm{CI}=1.16-1.57)$; watching television (five or more hours daily) $(\mathrm{PR}=1.40 ; 95 \% \mathrm{CI}=1.26-1.56)$ and falls in the previous year $(\mathrm{PR}=1.35 ; 95 \% \mathrm{CI}=1.10-1.66)$. Elderly persons living alone also had worse eating habits, with a less frequent intake of meat, beans and salads than their counterparts who lived with others. Conclusion: elderly persons living alone in Brazil have a worse health status and health-related habits. These findings represent a challenge and should motivate social and health policies aimed at fulfilling the greater needs of adults who grow old alone.

\footnotetext{
Universidade de São Paulo, Faculdade de Saúde Pública, Departamento de Epidemiologia, Programa de pós-graduação em Epidemiologia. São Paulo, São Paulo, Brasil.

Funding: National Council of Scientific and Technological Development (CNPq), 301968/2014-4, Productivity grant.

Etienne Larissa Duim Negrini'

Carla Ferreira do Nascimento ${ }^{1}$ Alexandre da Silva ${ }^{1}$ José Leopoldo Ferreira Antunes'

Keywords: Housing. Health Status Disparities. Epidemiology. 


\section{INTRODUCTION}

Like other middle-income countries, Brazil has undergone an accelerated process of population aging in recent decades. This transition is directly related to the reduction in infant and child mortality throughout the twentieth century, as well as to a decline in fertility and an increase in life expectancy since the $1950 \mathrm{~s}^{1}$.

Households that include elderly persons are expected to provide the first nucleus of social interaction and support for such individuals, thus influencing their access to goods and resources. Poor housing conditions and disorganized households have been reported as contributing to the risk and progression of disability ${ }^{2}$. As new paradigms related to aging have emerge, the large number of people that live alone is considered to be one of the most important changes in contemporary societies ${ }^{3}$.

The present study was motivated by the perception of changes in household arrangements that have followed the accelerated process of aging in Brazilian society. Population projections estimate the proportion of elderly persons in Brazil in 2050 to be higher than the global average ${ }^{4}$. Despite this fact, the country continues to make slow progress towards providing adequate social protection in old age.

Family organization is dynamic, and household arrangements have changed over time in consonance with social change. A growing contingent of elderly persons has opted to or been induced to live alone. The increase in longevity and the historical decline in fertility, which are characteristics of demographic transition, have resulted in new patterns of behavior, new living arrangements, and prolonged periods of widowhood without the company of family members. These changes have resulted in a large number of elderly persons with few or no close family members, while the proportion of one-person households in Brazil has grown since the 1970s ${ }^{5}$.

Growing old while living alone (defined by living in one-person households), without the support of close kinship, can be associated in different ways with various health outcomes, including death ${ }^{6}$. It has been reported in several sizeable longitudinal assessments that loneliness and a lack of personal networks are associated with mortality risk ${ }^{7-10}$. In any case, the prospects for the household arrangements of elderly persons in Brazil is uncertain. Few studies have assessed this theme, resulting in the lack of a clear depiction of their needs and potential demand for health services and social support ${ }^{3,11}$.

The objective of the present study was to describe the elderly persons living alone in Brazil and how they live, in terms of specific features of their health profile.

\section{METHODS}

\section{Population and study design}

This cross-sectional study assessed information collected by the National Health Survey of the Ministry of Health and the Brazilian Institute of Geography and Statistics in 2013. A probabilistic sample was employed to allow statistical inference for the whole country and each of its five geographic regions. The sample was stratified into clusters in three stages: census tracts (the primary sampling units), households and individuals. A previous report provided more extensive information about the sample design, sample size calculation, and weighting ${ }^{12}$.

A total of 64,308 individuals aged 18 years or older were interviewed between August and November 2013, corresponding to a response rate of $86 \%$. Questionnaires were applied during household visits by specially trained interviewers. The study exclusively considered information related to individuals aged 60 years or older $(\mathrm{N}=11,967)$. The survey observed international guidelines on ethics in research involving human subjects. Participants signed a consent form, and the National Research Ethics Committee approved the project in June 2013 (No. 10853812.7.0000.0008).

Variables

The present study assessed the prevalence of old people living alone, defined as individuals aged 60 or over residing in one-person households. This condition was the primary variable of the study. 
Brazil has five geographic regions, with the north and northeast the poorest; their per capita gross domestic product is nearly half that of the remaining regions.

Socio-demographic information was collected (gender, age group, ethnicity/skin color, schooling, and per capita income). The classification of ethnicity/ skin color observed standards used in censuses carried out in Brazil, with self-reported information on the following categories: white (European descent), brown (mixed race), black (African descent), yellow (Asian descent) and indigenous. In Brazil, less than four years of formal education represents insufficient schooling; eight years corresponds to a complete elementary education; eleven years corresponds to a complete secondary education; fourteen years represents a university education. Income was classified by tertiles, according to an OECD equivalence scale that divides household income by the square root of the number of residents of the household ${ }^{13}$.

Regarding health conditions, the interviewer asked whether a doctor had ever diagnosed hypertension, diabetes, high cholesterol, coronary heart disease, stroke, asthma, arthritis or rheumatism, spinal problems, work-related musculoskeletal disorders, depression, other mental illnesses, chronic obstructive pulmonary disease, cancer, kidney failure or other chronic diseases. Responses were classified according to the number of diseases reported. The prevalence of hearing loss and physical disability (paralysis, amputation, deformity, motor deficiency, ostomy, and dwarfism) were also registered. The variable "disease in the previous two weeks" was assessed by asking if the informant had stopped performing any of their usual activities due to health reasons during that period.

The questionnaire included information on functional disabilities. Basic activities of daily living comprise the ability to feed or bathe oneself, use the bathroom, dress, walk indoors and get up from the bed or a chair ${ }^{14}$. Instrumental activities of daily living comprise the ability to buy food, take care of money, go to the doctor, take medicines or use transportation $^{15}$. Each of these activities has the following options: (i) without difficulty, (ii) a little difficulty, (iii) great difficulty, and (iv) failure to perform. The dichotomous classification of responses considered option (i) as "no," and the remaining options as "yes," as suggested by Espelt et al. ${ }^{16}$. The questionnaire also recorded the use of a walking stick, the occurrence of falls in the previous year and participation in social activities organized by religious or social groups, clubs, social centers for the elderly and others.

Behavioral characteristics included indicators of dietary patterns (consumption of beans and salad every day, meat five or more times per week) and the habit of watching television for five or more hours a day.

\section{Statistical analysis}

The distribution of elderly persons according to the variables of interest was described and the association between these variables was analyzed. The prevalence of individuals living alone was assessed as an outcome according to geographic region and the socio-demographic factors of the analysis. The prevalence of elderly persons living in one-person households was considered a factor in the assessment of outcomes related to health conditions, functional disabilities and behaviors.

Poisson regression models were used to evaluate prevalence ratios and their respective 95\% confidence intervals. Confidence intervals encompassing values greater than one indicate that the comparison group had a higher prevalence than the reference value. The inverse occured when confidence intervals encompassed values lower than one. Complementarily, there was no statistically significant association when the confidence interval encompassed the unit.

All analyzes were conducted using Stata 14 (College Station, TX, USA, 2015) software, taking into account the complex sample design and sample weights.

\section{RESULTS}

The proportion of elderly persons living alone in Brazil was 15.3\% (14.4\%-16.2\%, 95\% confidence interval) in 2013. This proportion varied geographically, with the more affluent portion of the country (the south, southeast and center-west 
regions) having higher figures than the poorer north and northeast regions (table 1).

The prevalence of elderly individuals living in one-person households was 29\% higher among women than among men. This condition was also more prevalent among older elderly persons, affecting nearly one out of every five individuals aged 75 years or older $(p<0.001)$. No significant difference occurred across racial strata and education levels. However, the assessment of income distribution showed a significantly higher proportion of individuals living alone among the most deprived tertile (table 2).

Table 1. Who are they? Prevalence of elderly persons living alone in each geographic region. Brazil, 2013 (N=11,967).

\begin{tabular}{lllll}
\hline Geographic region & Prevalence & $\mathrm{PR}^{1}$ & $95 \% \mathrm{CI}^{2}$ & $P$ \\
\hline Southeast & 15.9 & 1.00 & & \\
South & 17.8 & 1.12 & $0.97-1.30$ & 0.132 \\
Centre-West & 15.4 & 0.97 & $0.82-1.14$ & 0.721 \\
North & 11.9 & 0.75 & $0.60-0.94$ & 0.013 \\
Northeast & 13.3 & 0.84 & $0.73-0.97$ & 0.017 \\
\hline
\end{tabular}

${ }^{1}$ Prevalence ratio; ${ }^{2}$ 95\% Confidence Interval.

Table 2. Who are they? Prevalence of elderly persons living alone according to socio-demographic characteristics. Brazil, 2013 ( $\mathrm{N}=11,967)$.

\begin{tabular}{|c|c|c|c|c|}
\hline Socio-demographic characteristics & Prevalence & $\mathrm{PR}^{1}$ & $95 \% \mathrm{CI}^{2}$ & $P$ \\
\hline \multicolumn{5}{|l|}{ Gender } \\
\hline Female & 17.0 & 1.29 & $1.14-1.45$ & $<0.001$ \\
\hline Male & 13.2 & 1.00 & & \\
\hline \multicolumn{5}{|l|}{ Age } \\
\hline $60-64$ & 11.5 & 1.00 & & \\
\hline $65-69$ & 15.3 & 1.33 & $1.13-1.57$ & 0.001 \\
\hline $70-74$ & 15.5 & 1.35 & $1.13-1.62$ & 0.001 \\
\hline 75 or more & 20.0 & 1.75 & $1.49-2.04$ & $<0.001$ \\
\hline \multicolumn{5}{|l|}{ Ethnicity/skin color } \\
\hline White & 15.6 & 1.00 & & \\
\hline Brown & 14.9 & 0.95 & $0.84-1.07$ & 0.428 \\
\hline Black & 15.2 & 0.97 & $0.78-1.20$ & 0.775 \\
\hline Yellow & 14.5 & 0.93 & $0.55-1.55$ & 0.768 \\
\hline Indigenous & 16.2 & 1.04 & $0.51-2.09$ & 0.923 \\
\hline \multicolumn{5}{|l|}{ Years of study } \\
\hline $0-3$ & 15.2 & 1.00 & & \\
\hline $4-7$ & 14.7 & 0.96 & $0.84-1.11$ & 0.620 \\
\hline $8-10$ & 16.9 & 1.11 & $0.92-1.34$ & 0.268 \\
\hline $11-13$ & 15.3 & 1.00 & $0.83-1.21$ & 0.970 \\
\hline 14 or more & 15.5 & 1.01 & $0.83-1.25$ & 0.889 \\
\hline \multicolumn{5}{|l|}{ Income } \\
\hline 1st tertile & 23.0 & 2.06 & $1.78-2.40$ & $<0.001$ \\
\hline 2nd tertile & 11.8 & 1.06 & $0.90-1.25$ & 0.488 \\
\hline 3rd tertile & 11.1 & 1.00 & & \\
\hline
\end{tabular}

${ }^{1}$ Prevalence ratio; ${ }^{2}$ 95\% Confidence Interval. 
The assessment of health conditions revealed important differences between elderly individuals who lived alone and their counterparts who lived with family members or others. The prevalence of people who stated they had suffered from illness in the two weeks prior to the study was nearly one third higher among the former than the latter group (PR: 1.35, 95\% CI 1.16-1.57). No significant difference was observed between the two groups in terms of number of chronic diseases, nor in the prevalence of any chronic diseases, except for arthritis or rheumatism, with a worse profile for those living alone (PR: 1.18, 95\% CI 1.03 -1.36). Furthermore, elderly persons who lived alone had a significantly higher prevalence of hearing loss (PR: 1.57, 95\% CI: 1.27-1.93) (table 3).

When considering functional mobility, the prevalence of difficulties in activities of daily living (ADL) $(p=0.211)$ and the use of a walking stick $(\mathrm{p}=0.155)$ did not differ significantly between elderly persons who lived alone and those who lived with others. However, the first group had a significantly higher prevalence of self-reported difficulties in instrumental ADL (PR: 1.15, 95\% CI: 1.04-1.28) and falls during the previous twelvemonth period (PR: 1.35, 95\% CI: 1.10-1.66) (table 4).

The assessment of behavioral characteristics depicted better dietary patterns among elderly persons who lived with others than among those who lived alone. The former group included a significantly higher proportion of individuals who ate beans $(p<0.001)$ and salads $(p=0.045)$ on a daily basis, and who ate meat five or more times per week ( $p=0.019)$. In terms of watching television for five or more hours each day, which is considered detrimental sedentary behavior, the prevalence was $40 \%$ higher among those who lived alone (PR: 1.40, 95\% CI: 1.26-1.56) (table 5).

Table 3. How do they live? Prevalence of health conditions among elderly persons living alone and living with others. Brazil, 2013 ( $\mathrm{N}=11,967)$.

\begin{tabular}{|c|c|c|c|c|c|c|}
\hline \multicolumn{2}{|l|}{ Health conditions } & $\begin{array}{l}\text { Living } \\
\text { alone }\end{array}$ & $\begin{array}{l}\text { Living with } \\
\text { others }\end{array}$ & $\mathrm{PR}^{1}$ & $95 \% \mathrm{CI}^{2}$ & $p$ \\
\hline \multicolumn{2}{|c|}{ Any disease in the previous 2 weeks } & 15.0 & 10.9 & 1.35 & $1.16-1.57$ & $<0.001$ \\
\hline \multirow[t]{2}{*}{ Chronic diseases } & One & 24.0 & 26.0 & 0.92 & $0.85-1.01$ & 0.076 \\
\hline & Two or more & 52.4 & 52.7 & 0.99 & $0.95-1.04$ & 0.228 \\
\hline \multicolumn{2}{|l|}{ Hypertension } & 49.1 & 51.5 & 0.95 & $0.89-1.02$ & 0.164 \\
\hline \multicolumn{2}{|c|}{ Arthritis or rheumatism } & 18.9 & 16.0 & 1.18 & $1.03-1.36$ & 0.021 \\
\hline \multicolumn{2}{|c|}{ Physical disability } & 3.4 & 3.5 & 0.97 & $0.68-1.39$ & 0.872 \\
\hline \multicolumn{2}{|l|}{ Hearing loss } & 11.6 & 7.4 & 1.57 & $1.27-1.93$ & $<0.001$ \\
\hline
\end{tabular}

${ }^{1}$ Prevalence ratio; ${ }^{2} 95 \%$ Confidence Interval.

Table 4. How do they live? Prevalence of functional disabilities among elderly persons living alone and living with others. Brazil, 2013 (N=11,967).

\begin{tabular}{|c|c|c|c|c|c|}
\hline Functional disabilities & Living alone & Living with others & $\mathrm{RP}^{1}$ & IC $95 \%$ & $p$ \\
\hline Difficulties in basic $\mathrm{ADL}^{2}$ & 16.7 & 15.3 & 1.10 & $0.95-1.26$ & 0.211 \\
\hline Difficulties in instrumental AIVD 3 & 30.4 & 26.3 & 1.15 & $1.04-1.28$ & 0.007 \\
\hline No social activities & 71.7 & 75.5 & 0.95 & $0.91-0.99$ & 0.012 \\
\hline Falls (in the last year) & 9.5 & 7.0 & 1.35 & $1.10-1.66$ & 0.004 \\
\hline Use of walking stick & 10.1 & 8.8 & 1.15 & $0.95-1.40$ & 0.155 \\
\hline
\end{tabular}

${ }^{1}$ Prevalence ratio; ${ }^{2}$ Basic activities of daily living; ${ }^{3}$ Instrumental activities of daily living. 
Table 5. How do they live? Prevalence of behavioral characteristics among older individuals living alone and living with others. Brazil, 2013 ( $\mathrm{N}=11,967)$.

\begin{tabular}{llllll}
\hline Behavioral characteristics & $\begin{array}{l}\text { Living } \\
\text { alone }\end{array}$ & $\begin{array}{l}\text { Living with } \\
\text { others }\end{array}$ & PR $^{1}$ & 95\% CI & $\mathrm{p}$ \\
\hline Eat beans (every day) & 49.2 & 61.0 & 0.81 & $0.76-0.86$ & $<0.001$ \\
Eat salad (every day) & 37.3 & 40.9 & 0.91 & $0.83-0.99$ & 0.045 \\
Eat meat (5 or more times per week) & 29.4 & 33.4 & 0.88 & $0.79-0.98$ & 0.019 \\
Watch television (5 or more hours per day) & 31.2 & 22.2 & 1.40 & $1.26-1.56$ & $<0.001$ \\
\hline
\end{tabular}

${ }^{1}$ Prevalence ratio.

\section{DISCUSSION}

The main results of the present study are that the elderly persons who live alone in Brazil are mostly women, deprived and older elderly individuals, who live in the more affluent regions of the country, and have poorer dietary habits, greater health needs, and more sedentary behavior.

Who are they?

In Brazil, lower-income individuals are choosing to or being forced to live alone during old age. Curiously, this pattern mostly affects the wealthier geographic regions of the country. The south and southeast had a higher proportion of old people living in one-person households than the poorer regions of Brazil. These regions also have a higher human development index, life expectancy and proportion of elderly people. Almost $18 \%$ of the population of the southern state of Rio Grande do Sul, for example, is aged 60 or over; whereas some northern states (such as Roraima and Amapá) have poorer socioeconomic indices, and the elderly make up only $8 \%$ of the overall population ${ }^{4}$.

Geographic differences in the demographic transition and the consequent higher proportion of old people in the population to some extent reflect the historical process of the occupation of Brazil over consecutive economic cycles. The wealthier Brazilian regions received a higher influx of immigration, both from abroad and from other Brazilian states, and encouraged industrialization and public services ${ }^{17}$. These conditions provided improved conditions of social security and retirement, as well as opportunities for elderly individuals to remain in the labor market ${ }^{18}$. Notwithstanding the greater proportion of elderly persons who live alone in prosperous regions, results reported here suggest that better-off individuals try to avoid living alone, even in prosperous regions.

It was also found that women and older elderly persons are more likely to live alone than their respective counterparts. The elderly population in Brazil is mostly composed of women, with their percentage participation tending to increase among older groups ${ }^{1}$. However, the increased proportion of women among the elderly population and the higher likelihood of elderly women living alone have also been found in other countries. Margolis and Verdery ${ }^{11}$ obtained similar results when assessing country-wide information in the US. In Europe, the proportion of elderly women who live alone also had a socioeconomic gradient, ranging from $24 \%$ in Cyprus to more than $45 \%$ in Norway, Finland, and Denmark ${ }^{19}$.

\section{How do they live?}

It was noteworthy that the prevalence of chronic diseases did not differ significantly between elderly persons who do and do not live alone; the same was found for physical disability, difficulties in basic activities of daily living and use of a walking stick. Sixsmith et al. ${ }^{20}$ stated that living alone can be an opportunity for greater self-knowledge and closer social ties outside the home environment, and it is reassuring to find that elderly individuals 
who live alone are not subject to a poorer profile of severe conditions. Living alone may have some attractive characteristics, though it demands certain strength and physical capabilities. Failing to fulfill these requirements may put the individual at a disadvantage, eventually overloading social services in terms of the long-term care and support they provide for the elderly.

Despite the relatively homogeneous distribution of chronic diseases among those who do and do not live alone, the present study found that the former had a poorer epidemiologic profile in terms of less severe conditions. More individuals who lived alone complained of a lack of social activities and of having been ill during the last previous weeks. They also had a higher prevalence of hearing loss, arthritis or rheumatism, and difficulties in instrumental activities of daily living. These findings draw attention to the more extensive health needs of this population segment, which should serve as a warning to the health authorities.

A nationally representative panel study of elderly persons in the US, the Health and Retirement Study 2015, also depicted a higher prevalence of disabilities among those who lived alone, in terms of instrumental activities of daily living ${ }^{2}$. Authors interpreted the reason for this as the fact that having a live-in partner may provide supportive resources for a healthier and more affluent life. Most solitary elderly persons in Brazil, like in the US, cannot rely on functional household arrangements. For those individuals, the health system may be required to supply additional services to fulfill their more extensive needs.

The results of the present study showed a significantly higher prevalence of hearing loss among elderly persons who lived alone. Previous studies have also reported the association between hearing impairment and social isolation ${ }^{21-23}$. A complex interplay is involved in this association as both conditions can influence the other, and they also reflect a lack of communication ability. This finding reinforces the need for closer attention to this population.
Elderly persons who live alone presented worse dietary patterns than those who live with others. Brazilian society has undergone a process of nutritional transition ${ }^{24}$, mainly through the largescale insertion of junk food in the daily menu of the population. Many studies have reported the increased consumption of ultra-processed foods in place of a more traditional diet, based on vegetables and minimally processed foods, which are a standard feature of the Brazilian food dynamics ${ }^{25,26}$. The current study suggests that this transition may have already reached the elderly, especially affecting those who live alone.

\section{Limitations and strengths}

The use of cross-sectional data - which cannot infer causality or temporal relationships between factors and outcomes - and relying on the selfreporting of the participants - with no registered information available - are the main limitations of this study. One of its strengths, however, is the use of a large sample, which was specifically designed to be representative of the country as a whole and each of its five geographic regions. A further strength is the setting of specific targets for the planning of health services aimed at this population group.

\section{CONCLUSION}

The present study described the prevalence of elderly persons living alone in Brazil, according to sociodemographic characteristics and the geographic region of residence. It also described the greater likelihood of elderly persons who live alone having a worse profile in critical outcomes in health status, physical functioning, and behavior. The information reported here is relevant for health policy and planning, as finding solutions for the functional decline in old age is a current need in many countries, and a task that becomes even more challenging in the context of loneliness. Healthcare strategies should consider providing surrogate social services to compensate for the absent familial support of solitary individuals in old age. 


\section{REFERENCES}

1. Camarano AA. The new demographic paradigm. Ciênc Saúde Colet. 2013;18(12):3446-7.

2. Henning-Smith C, Shippee T, Capistrant B. Laterlife disability in environmental context: why living arrangements matter. Gerontologist. 2017:1-23.

3. Klinenberg E. Social isolation, loneliness, and living alone: identifying the risks for public health. Am J Public Health. 2016;106(5):786-7.

4. Instituto Brasileiro de Geografia e Estatística, Coordenação de População e Indicadores Sociais. Síntese de indicadores sociais: uma análise das condições de vida da população brasileira. Rio de Janeiro: IBGE; 2016.

5. Melo NCV, Teixeira KMD, Barbosa TL, Montoya AJA, Silveira MB. Household arrangements of elderly persons in Brazil: analyses based on the national household survey sample. Rev Bras Geriatr Gerontol. 2016;19(1):139-51.

6. $\mathrm{Ng} \mathrm{KH}$. Future of family support: projected living arrangements and income sources of older people in Hong Kong up to 2030. Australas J Ageing. 2016;35(2):113-8.

7. Pimouguet C, Rizzuto D, Schön P, Shakersain B, Angleman S, Lagergren M, et al. Impact of living alone on institutionalization and mortality: a population-based longitudinal study. Eur J Public Health. 2016;26(1):182-7.

8. Ellwardt L, van Tilburg T, Aartsen M, Wittek R, Steverink N. Personal networks and mortality risk in older adults: a twenty-year longitudinal study. PLoS ONE. 2015;10(3):1-14.

9. Pantell M, Rehkopf D, Jutte D, Syme SL, Balmes J, Adler N. Social isolation: a predictor of mortality comparable to traditional clinical risk factors. Am J Public Health. 2013;103(11):2056-62.

10. Steptoe A, Shankar A, Demakakos P, Wardle J. Social isolation, loneliness, and all-cause mortality in older men and women. Proc Natl Acad Sci USA. 2013;110(15):5797-801.

11. Margolis R, Verdery AM. Older adults without close kin in the United States. J Gerontol Ser B Psychol Sci Soc Sci. 2017;72(4):688-93.

12. Souza Júnior PRB, Freitas MPS, Antonaci GA, Szwarcwald CL. Sampling design for the National Health Survey, Brazil 2013. Epidemiol Serv Saúde. 2015;24(2):207-16.
13. Organisation for Economic Co-operation and Development. Social Policy Division. Directorate for Employment, Labour and Social Affairs. Quality review of the OECD database on household incomes and poverty and the OECD earnings database. Part I. Paris: OECD; 2012.

14. Katz S, Ford AB, Moskowitz RW, Jackson BA, Jaffe MW. Studies of illness in the aged. The index of ADL: a standardized measure of biological and psychosocial function. JAMA. 1963;185(12):914-9.

15. Lawton MP, Brody EM. Assessment of older people: self-maintaining and instrumental activities of daily living. Gerontologist. 1969;9(3):179-86.

16. Espelt A, Font-Ribera L, Rodriguez-Sanz M, Artazcoz L, Ferrando J, Plaza A, et al. Disability among older people in a southern European city in 2006: trends in gender and socioeconomic inequalities. J Women's Health (Larchmt). 2010;19(5):927-33.

17. Villa SB. Os formatos familiares contemporâneos: transformações demográficas. Observatorium. 2012;4(12):2-26.

18. Maia AG, Sakamoto CS. The impacts of rapid demographic transition on family structure and income inequality in Brazil, 1981-2011. Popul Stud (Camb). 2016:70(3):293-309.

19. Reher D, Requena M. Elderly women living alone in Spain: the importance of having children. Eur J Ageing. 2017;14(3):311-22.

20. Sixsmith J, Sixsmith A, Fänge AM, Naumann D, Kucsera C, Tomsone S, et al. Healthy ageing and home: the perspectives of very old people in five European countries. Soc Sci Med. 2014;106:1-9.

21. Mick P, Parfyonov M, Wittich W, Phillips N, Kathleen Pichora-Fuller M. Associations between sensory loss and social networks, participation, support, and loneliness: analysis of the Canadian Longitudinal Study on Aging. Can Fam Physician. 2018;64(1):33-41.

22. Pronk M, Deeg DJ, Kramer SE. Hearing status in older persons: a significant determinant of depression and loneliness? results from the longitudinal aging study Amsterdam. Am J Audiol. 2013;22(2):316-20.

23. Sung YK, Li L, Blake C, Betz J, Lin FR. Association of hearing loss and loneliness in older adults. J Aging Health. 2016;28(6):979-94.

24. Conde WL, Monteiro CA. Nutrition transition and double burden of undernutrition and excess of weight in Brazil. Am J Clin Nutr. 2014;100(6):1617-22. 
25. Canella DS, Levy RB, Martins AP, Claro RM, Moubarac JC, Baraldi LG, et al. Ultra-processed food products and obesity in Brazilian households (20082009). PLoS ONE. 2014;9(3):1-7.
26. Monteiro CA, Moubarac JC, Cannon G, Ng SW, Popkin B. Ultra-processed products are becoming dominant in the global food system. Obes Rev. 2013;14(Suppl 2):21-8.

Received: May 29, 2018

Reviewed: August 09, 2018 